\title{
COVID-19: BIBLIOMETRIA E ANÁLISE DO PERFIL EPIDEMIOLÓGICO COMPARATIVO DE PACIENTES EM HOSPITAL DE REFERÊNCIA EM CAMPOS DOS GOYTACAZES
}

\author{
COVID-19: BIBLIOMETRY AND ANALYSIS OF THE COMPARATIVE EPIDEMIOLOGICAL \\ PROFILE OF PATIENTS IN A REFERENCE HOSPITAL IN CAMPOS DOS GOYTACAZES
}

\begin{abstract}
André Luiz Vargas ${ }^{1 *}$; Anna Barbosa Pinheiro Costa'; Karina Azevedo Lobo'; Tifany Bartolomeu da Silva'; Shaytner Campos Duarte ${ }^{2}$
\end{abstract}

1Monitores de Bioestatística FMC / Acadêmicos de Medicina da Faculdade de Medicina de Campos FMC 2Professor Doutor Faculdade de Medicina de Campos FMC. Professor Responsável Bioestatística.

* Autor de correspondência: andre.vargas.med55@gmail.com

\section{RESUMO}

O SARS-CoV-2 é um vírus da família Coronaviridae, que afeta principalmente o trato respiratório inferior. Os principais sintomas são: febre, tosse, dispneia e fadiga. A confirmação de casos de COVID19 pode ser por critério clínico, por critério clínicoepidemiológico, clínico-imagem ou por critério laboratorial. A descrição e a interpretação de dados epidemiológicos são de fundamental importância para que os gestores de saúde públicos e privados, além de pesquisadores realizem novas estratégias direcionadas para antecipação, controle e evolução do tratamento, enquanto problema de saúde pública. Objetivo: Traçar o perfil clínicoepidemiológico dos pacientes admitidos em um hospital de referência, acometidos com COVID-19 comparativamente a um estudo bibliométrico. Métodos: Estudo transversal, retrospectivo e descritivo, com abordagem quantitativa, com dados coletados nos prontuários de todos os pacientes diagnosticados com COVID-19 em um dos hospitais de referência, durante o ano de 2020. Resultados: Foram 4753 prontuários analisados, no qual o gênero feminino prevaleceu; faixa etária predominante foi de adultos com idade média de 43 anos; o tempo médio de internação foi de 10 dias; a taxa de óbito dos pacientes foram todas registradas na UTI, sendo de $84 \%$ para o sexo feminino e $90 \%$ para o sexo masculino, não houve óbitos registrados nos demais setores do hospital. No ranking de publicações totais sobre COVID-19 na base Scopus, o Brasil está em $11^{\circ}$ lugar, 3,19\% das publicações. Conclusão: O percentual de óbitos no Município de

\section{ABSTRACT}

SARS-CoV-2 is a virus in the Coronaviridae family, which mainly affects the lower respiratory tract. The main symptoms are: fever, cough, dyspnoea and fatigue. Confirmation of COVID-19 cases can be based on clinical criteria, clinical-epidemiological criteria, clinical-image criteria or laboratory criteria. The description and interpretation of epidemiological data are of fundamental importance so that public and private health managers, in addition to researchers, carry out new strategies aimed at anticipating, controlling and evolving treatment, as a public health problem. Objective: To trace the clinical-epidemiological profile of patients admitted to a referral hospital, affected by COVID-19 compared to a bibliometric study. Methods: Cross-sectional, retrospective and descriptive study, with a quantitative approach, with data collected from the medical records of all patients diagnosed with COVID-19 in one of the reference hospitals, during the year 2020. Results: There were 4753 medical records analyzed, in which the female gender prevailed; the predominant age group was adults with an average age of 43 years; the average hospital stay was 10 days; the death rate of patients was all registered in the ICU, $84 \%$ for females and $90 \%$ for males, there were no deaths recorded in the other sectors of the hospital. In the ranking of total publications on COVID-19 in the Scopus database, Brazil is in 11th place, $3.19 \%$ of the publications. Conclusion: The percentage of deaths in the Municipality of Campos dos Goytacazes is lower than that of Rio de Janeiro and the national 
Campos dos Goytacazes é inferior à do Rio de Janeiro e a taxa nacional, sendo esse percentual maior em idosos e pessoas do sexo masculino. Já o tempo de internação é semelhante entre homens e mulheres em UTI. O Brasil tem forte participação nas publicações mundiais sobre COVID-19 via Scopus.

PALAVRAS-CHAVE

Coronavirus; COVID-19; SARS-CoV-2; Hospital.

\section{INTRODUÇÃO}

O SARS-CoV-2 é um vírus da família Coronaviridae (GUTIERREZ, et al., 2020), que contém cerca de 30.000 bases de RNA de fita simples. Afeta principalmente o trato respiratório inferior, em casos graves pode produzir uma resposta inflamatória sistêmica e fenômenos trombóticos em diferentes órgãos a nível vascular, renal e até neurológico (ALVES, et al., 2020).

Se tornou uma ameaça iminente para toda a humanidade por ser o agente causador da pandemia COVID-19, que levou à declaração de emergência sanitária global pela Organização Mundial da Saúde (OMS) e a estabelecer medidas rígidas de controle para evitar a disseminação em larga escala (GUTIERREZ, et al., 2020). A OMS, em 11 de março de 2020, declarou situação de pandemia pela COVID-19. Em 9 de julho do mesmo ano, foram relatados mais de 11,8 milhões de casos e 544 mil óbitos no mundo (FLORIANI, et al., 2020).

A infecção ocorre através da ligação da proteína $S$ ao receptor da enzima conversora de angiotensina 2 na superfície da célula humana. A partir disso, observa-se uma redução na disponibilidade dessa enzima, amplamente expressa em vários tecidos do corpo humano, especialmente em pulmões, coração e endotélio, com distúrbio na modulação do sistema reninaa ng iotensina-aldosterona (SRAA). Consequentemente, há um aumento da expressão de angiotensina 2 e ações deletérias ao organismo (BRANDÃO, et al., 2020).

O desequilíbrio no SRAA contribui para um estado pró inflamatório, pró-oxidativo, com recrutamento de macrofagos, excesso de citocinas circulantes, aumento na liberação de aldosterona, lesão tecidual e disfunção de múltiplos órgãos, característicos da forma grave da COVID. Todas essas alterações desencadeadas pelo SARS-CoV-2 podem prejudicar a função endotelial; assim como, rate, with this percentage being higher in the elderly and in males. The length of stay is similar for men and women in the ICU. Brazil has a strong participation in worldwide publications on COVID-19 via Scopus.

KEYWORDS:

Coronavirus; COVID-19; SARS-CoV-2; Hospital.

comorbidades ligadas ao endotélio atribuem maior gravidade à doença. Logo, a fisiopatogenia da COVID19 se interliga entre fatores pró-inflamatórios e prótrombóticos, tornando-os importantes alvos terapêuticos para controle da doença (BRANDÃO, et al., 2020). Ocorre disfunção endotelial causada por infecção ativa uma geração excessiva de trombina e inibe fibrinólise, que designa hipercoagulabilidade. A linfopenia é frequente em pacientes com COVID-19 (ASSELAH,et al., 2020) e a síndrome do desconforto respiratório agudo provocada pelo COVID-19, resulta em danos alveolares difusos com formação de membrana hialina com fibrina deposição e algumas células aumentadas multinucleadas (ASSELAH,et al., 2020).

Os processos fisiopatológicos interligados são: Efeito citopático direto, decorrente da infecção viral, que predomina nos estágios iniciais da doença; e a Resposta inflamatória desregulada do hospedeiro, que predomina nas fases posteriores, que conta com um estágio de imunossupressão que segue a fase pró-inflamatória. É caracterizada por uma depleção funcional de linfócitos especialmente linfócitos T e CD8 CD4 (ALVES, et al., 2020)

Os principais sintomas são febre (temperatura axilar maior que $37.8^{\circ} \mathrm{C}$ ), tosse, dispneia e fadiga. Podendo apresentar também odinofagia, vômito e diarreia. Nos exames laboratoriais observa-se leucopenia, linfocitopenia, aumento significativo da Proteína C Reativa (PCR) e da Velocidade de Hemossedimentação (VHS). O nível de PCR tem um bom valor preditivo para a possibilidade de eventos graves em pacientes idosos com Covid-19. Em grande parte das tomografias computadorizadas de tórax, encontra-se pneumonia bilateral e opacidade em vidro fosco. (GUAN et al.,2020) (TIAN et al.,2020) (WANG,R. et al., 2020) (WANG,G. et al.,2020)

A confirmação de casos de COVID-19 pode ser por critério clínico, por critério clínico- 
epidemiológico, clínico-imagem ou por critério laboratorial. Quando o indivíduo apresenta síndrome gripal (SG) ou síndrome respiratória aguda grave (SRAG) associado a anosmia ou ageusia sem outra causa pregressa, pode-se considerar como um caso confirmado. Pelo critério clínicoepidemiológico é considerado quando o indivíduo apresenta SG ou SRAG com histórico de contato próximo com caso confirmado de COVID-19 nos 14 dias anteriores ao aparecimento dos sintomas. Por critério clínico-imagem é considerado quando indivíduo com SG ou SRAG ou óbito por SRAG no qual não foi possível a confirmação por critério laboratorial e que apresente uma das seguintes alterações na tomografia computadorizada: opacidade em vidro fosco multifocal de morfologia arredondada com ou sem consolidação ou linhas intralobulares visíveis; Opacidade em vidro fosco periférico, bilateral, com ou sem consolidação ou linhas intralobulares visíveis; Sinal de halo reverso ou outros achados de pneumonia em organização. Por critério laboratorial é considerado quando o indivíduo com SG ou SRAG faz o teste de biologia molecular detectando SARS-CoV-2 feito pelo método RT-PCR em tempo real ou realiza a pesquisa de antígeno reagente para SARA-CoV-2 por imunocromatografia para detecção de antígeno ou teste imunológico com resultado reagente para IgM, IgA e/ou IgG realizado pelos métodos Imunoensaio por Eletroquimioluminescência (ECLIA), imunocromatografia (teste rápido) para detecção de anticorpos ou Ensaio imunoenzimático (EnzymeLinked Immunosorbent Assay - ELISA). Indivíduos assintomáticos podem ser considerados casos confirmados para COVID-19 se realizarem o exame de biologia molecular detectando SARS-CoV-2 pelo método RT-PCR em tempo real ou pelo exame imunológico com resultado reagente para IgM e/ou IgA pelo método ensaio imunoenzimático ou imunocromatografia. É válido ressaltar que nos casos da COVID-19 a Imunoglobulina A (IgA) tem positivado mais precocemente, motivo de ser escolhida a pesquisa dessa imunoglobulina. (MINISTÉRIO DASAÚDE, 2020) (NOGUEIRA, 2020).

Alguns cientistas concluíram que os casos de reinfecção nos dizem que não podemos confiar na imunidade adquirida por infecção natural para conferir imunidade de rebanho (BRÜSSOW, 2020).

Todos os casos de Síndrome gripal, de síndrome respiratória aguda grave e óbito por SRAG devem ser notificados. Os indivíduos assintomáticos, mas com confirmação laboratorial de infecção recente por COVID-19 também devem ser notificados. A notificação deve ser realizada por profissionais de saúde e instituições de saúde no período de $24 \mathrm{~h}$ a partir da suspeita inicial do caso. (MINISTÉRIO DA SAÚDE, 2020)

Estão sendo utilizadas diversas intervenções farmacológicas para o tratamento da COVID-19, muitas delas necessitando de aprovação de eficácia e segurança. Dentre os protocolos, o uso rotineiro de Hidroxicloroquina, cloroquina, azitromicina, lopinavir/ ritonavir, corticoides ou tocilizumabe não apresenta nenhum embasamento de eficácia do seu uso. $\mathrm{O}$ uso de Heparina pode ser feito em doses para profilaxia em caso de hospitalização e com minuciosa indicação clínica. Em relação aos antibacterianos, podem ser julgados em pacientes com suspeita de infecção bacteriana. Dessa forma, até o presente momento não existe tratamento farmacológico comprovado que garanta efetividade e segurança em seu uso rotineiro, por isso o tratamento deve ser feito de acordo com a individualidade do paciente. (FALAVIGNA, 2020)

A descrição e a interpretação de dados epidemiológicos são de fundamental importância para que os gestores de saúde públicos e privados, além de pesquisadores realizem novas estratégias direcionadas para antecipação, controle e evolução do tratamento, enquanto problema de saúde pública.

A bibliometria constitui uma eficiente forma de mensurar e diagnosticar os esforços de pesquisa e publicação relacionados a determinado tema. Este ramo da ciencitometria pode contribuir fornecendo dados estatísticos a respeito da evolução temporal, concentração geográfica de esforços, áreas que mais tem investido, dentre outras informações interessantes.

Nesse sentido, uma análise bibliométrica sobre essa produção científica crescente se torna importante, por ser capaz de produzir indicadores que mostram o grau de desenvolvimento dessa área do conhecimento. Para ARAúJO (2006), a bibliometria é uma técnica quantitativa e estatística de medição dos índices de produção e disseminação do conhecimento científico. Na mesma linha, MARTINS et al. (2016) afirma que a bibliometria auxilia os pesquisadores a conhecerem produções acadêmicas sobre um determinado assunto ou área, tornando-se uma pesquisa da disseminação e utilização dos estudos feitos e publicados. 
A Scopus é uma base de dados multidisciplinar, criada pela editora Elsevier em 2004, que cobre conteúdos publicados desde 1960. A base é atualizada diariamente, incluindo 21.000 títulos de mais de 5.000 editoras internacionais, 20.000 periódicos revisados por pares, 390 publicações comerciais, 370 séries de livros, 5,5 milhões de documentos de conferências, "Articlesin-Press" de mais de 3.850 periódicos e editoras, sendo fonte para bibliotecários, especialistas em informação, pesquisadores e editores (ELSEVIER, 2018).

\section{OBJETIVOS}

O objetivo do presente estudo foi traçar o perfil clínico-epidemiológico dos pacientes admitidos em um hospital de referência, acometidos com COVID-19 comparativamente a um estudo bibliométrico, usando a base de dados "Scopus", a respeito do termo "COVID", possibilitando assim avaliar a produção científica nacional e internacional do tema.

\section{METODOLOGIA}

Estudo transversal, retrospectivo e descritivo, com abordagem quantitativa, com dados coletados nos prontuários de todos os pacientes diagnosticados com COVID-19 em um dos hospitais de referência, durante o ano de 2020. O banco de dados, bem como as tabelas e gráficos foram extraídos de prontuários eletrônicos e construídos no MicrosoftExcel ${ }^{\circledR} 2010$.

A coleta de dados na base Scopus, do período de 2006 à 2021/Janeiro, disponível no Portal Periódicos da Capes, foi realizada no dia 05 de fevereiro de 2021, sendo usados os termos booleanos "Covid" e "Covid-19".

Iniciando-se as buscas pelos termos encontrarmos artigos publicados no mundo 97817, e ao inserirmos filtros para publicações brasileiras com o termo "Brazil" chegamos a 3240 artigos publicados na base Scopus entre os anos de 2006 e 2021/janeiro.

Foi possível extrair, além do total de artigos publicados na base Scopus e do total de publicações brasileiras, informações relacionadas à quantidade de artigos por ano, autor, instituição, país, área e periódico.

\section{RESULTADOS}

A tabela 1 demonstra dados descritivos por sexo, tempo de internação e idade dos pacientes que foram a óbito. Foram 4753 prontuários foram analisados, no qual o gênero feminino prevaleceu; faixa etária predominante foi de adultos com idade média de 43 anos; o tempo médio de internação foi de 10 dias; a taxa de óbito dos pacientes foram todas registradas na UTI, sendo de $84 \%$ para o sexo feminino e $90 \%$ para o sexo masculino, não houve óbitos registrados nos demais setores do hospital.

Tabela 1: № de casos, tempo de internação e idade dos óbitos por sexo.

\begin{tabular}{|c|c|c|c|}
\hline & $\mathrm{N}$ & $\begin{array}{c}\text { Tempo médio de } \\
\text { Internação }\end{array}$ & $\begin{array}{c}\text { Idade média } \\
\text { óbitos }\end{array}$ \\
\hline Sexo masculino & $2238(47 \%)$ & 10 dias & 74 anos \\
\hline Sexo feminino & $2515(53 \%)$ & 10 dias & 68 anos \\
\hline
\end{tabular}

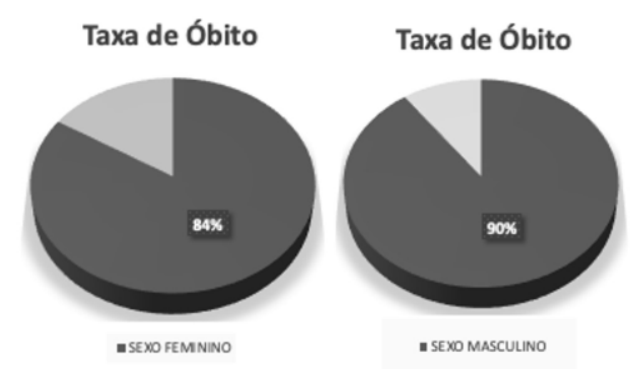

Figura 1: Taxa de óbitos em UTI

Todos os casos de óbito foram registrados na UTI, sendo o percentual de pacientes do sexo feminino (SF) que evoluíram para óbito de $84 \%$ e do sexo masculino (SM) de $90 \%$.

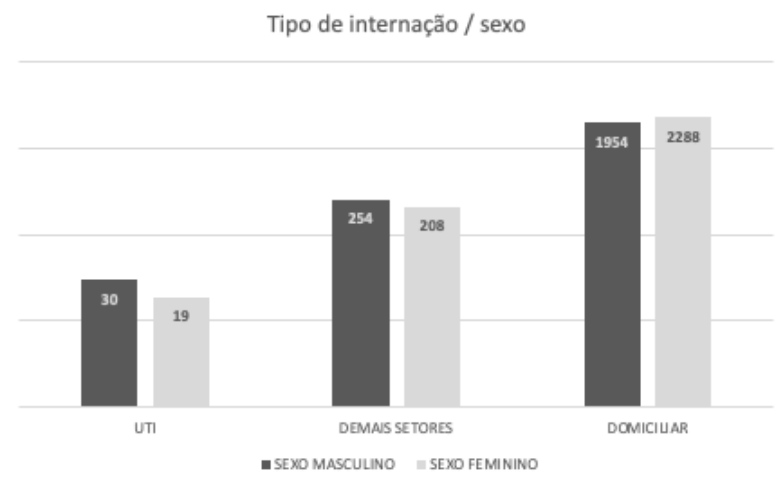

rigura L: INumero ae casos ae LUVIU- $\perp$ y por npo de atendimento/internação

Na Unidade de Terapia Intensiva foram internados 30 pacientes do sexo masculino e 19 do 
sexo feminino com COVID-19. Nos demais setores foram internados com COVID-19, 254 pacientes do sexo masculino e 208 do sexo femino.1954 pessoas do sexo masculino e 2288 do sexo feminino com COVID-19 fizeram isolamento domiciliar.

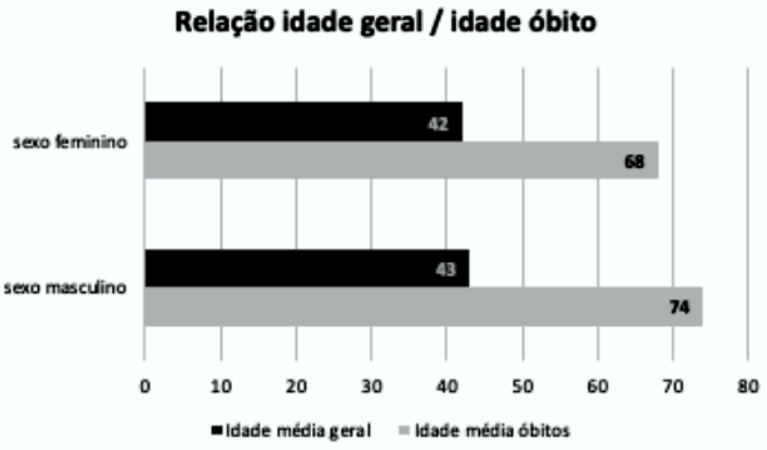

Figura 3: Relação Sexox x Idade de óbito

A idade média dos pacientes do sexo feminino com COVID-19 é de 42 anos, a idade média dos pacientes do sexo feminino que foram a óbito por COVID-19 é de 68 anos. Já no sexo masculino é de 43 anos a idade média dos pacientes do sexo masculino com COVID-19 e de 74 anos idade média dos pacientes do sexo masculino que foram a óbito por COVID-19.

\begin{tabular}{|l|c|c|c|}
\hline Dados até 01/12/2020 & Casos confirmados & Óbitos & Percentual de óbitos \\
\hline Brasil & 6.388 .526 & 173.862 & $2,8 \%$ \\
\hline Rio de Janeiro & 357.982 & 22.683 & $6,3 \%$ \\
\hline Campos dos Goytacazes & 11.077 & 471 & $4,3 \%$ \\
\hline Hospital alvo dos estudos & 4.753 & 43 & $0,9 \%$ \\
\hline
\end{tabular}

"Tabela ajustada pelos autores.

Fonte: Prefeitura de Campos (2021), Saúde RJ, (2021), G1 (2021).

Tabela 2: Dados descritivos de casos de COVID-19

No Brasil, até dia 01/12/2020, tem 6.300 .000 casos confirmados, 174.000 óbitos, sendo de $2,8 \%$ o percentual de óbitos. No Rio de Janeiro, 357.000 casos confirmados, 22.683 óbitos e $6,3 \%$ o percentual de óbitos. Em Campos dos Goytacazes, 11.077 casos confirmados, 471 óbitos e $4,3 \%$ o percentual de óbitos. E no hospital alvo dos estudos, 4.753 casos confirmados, 43 óbitos e 0,9\% o percentual de óbitos.

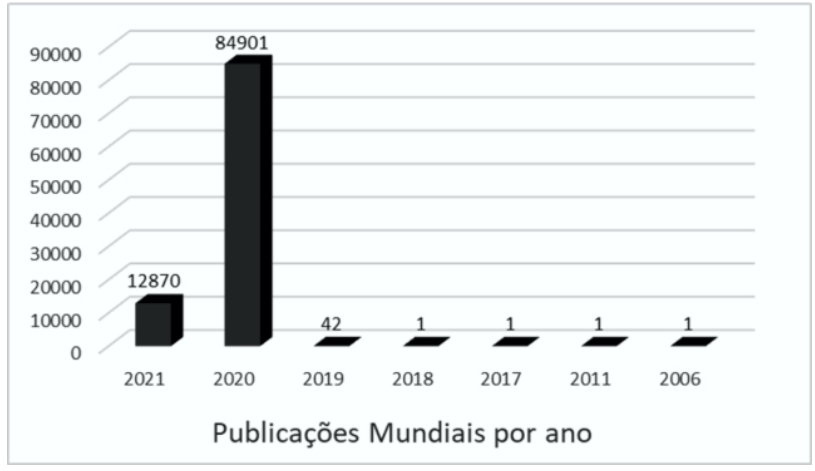

Figura 4: Publicações mundiais sobre COVID-19 base Scopus

Em relação às publicações mundiais sobre COVID-19 na base Scopus, foi publicado um artigo em 2006, um artigo em 2011, um artigo em 2017, um artigo em 2018, 42 artigos em 2019, 84901 artigos em 2020 e 12870 artigos em 2021, até o presente estudo.

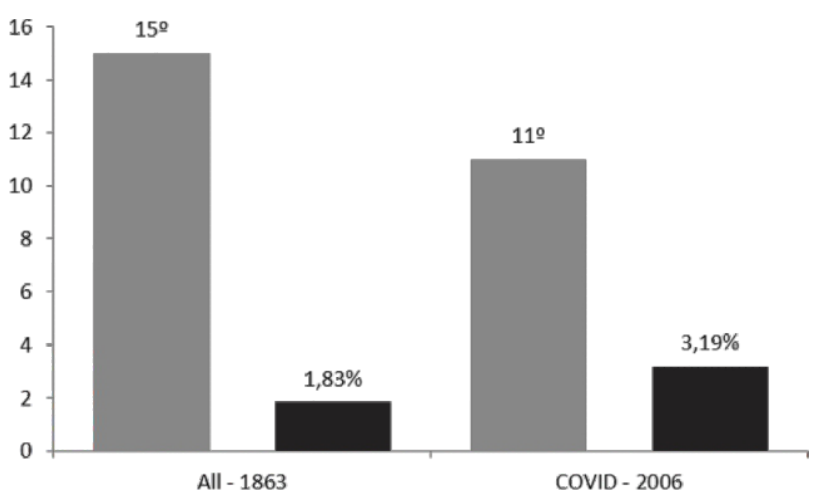

Figura 5: Ranking de publicações totais e acerca do COVID-19, classificação BRASIL.

No ranking de publicações totais na base Scopus, o Brasil está em $15^{\circ}$ lugar, 1,83\% das publicações. Nas publicações sobre COVID, o Brasil está em $11^{\circ}$ lugar no ranking, correspondendo a 3,19\% das publicações.

O International Journal of Environmetal teve mais de 800 publicações, sendo o que mais produziu no mundo. Já no Brasil, quem teve mais publicações foram os cadernos de saúde pública com quase 70 publicações.

O autor que mais publicou sobre covid-19 no mundo foi Mahase, E, com mais de 130 publicações. Já no Brasil, o autor Martins Filho P.R e o Giovanetti $M$. tiveram maior número de publicações. 
Top 10 Journals Mundo

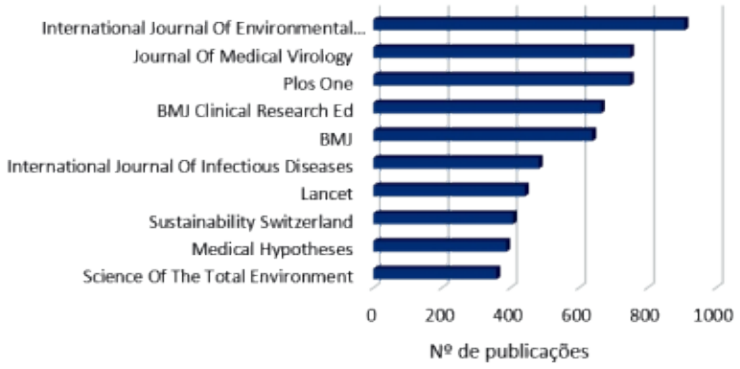

Top 10 Journals Brasil

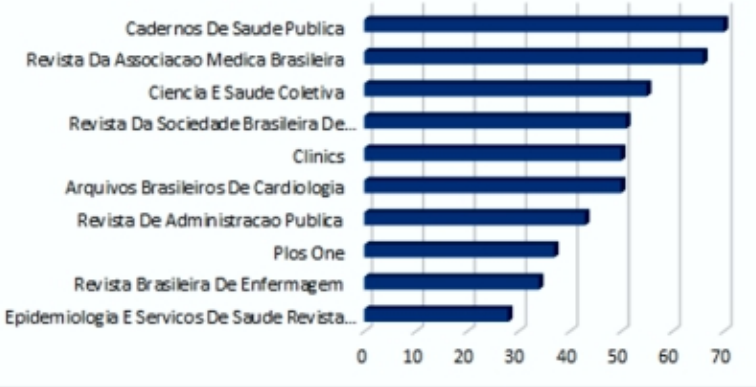

Figura 6: Número de publicações COVID-19 do mundo e no Brasil por periódicos.

Top 10 autores Mundo

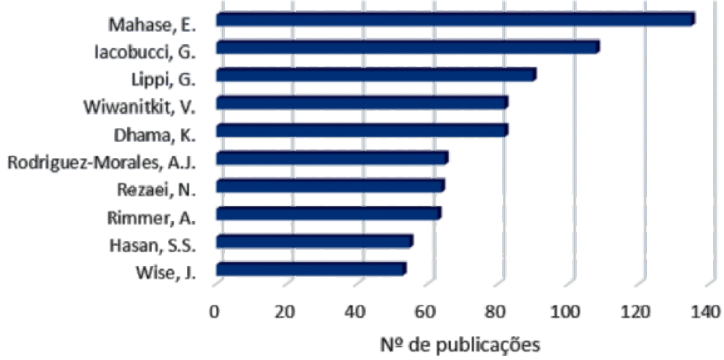

Top 10 autores Brasil

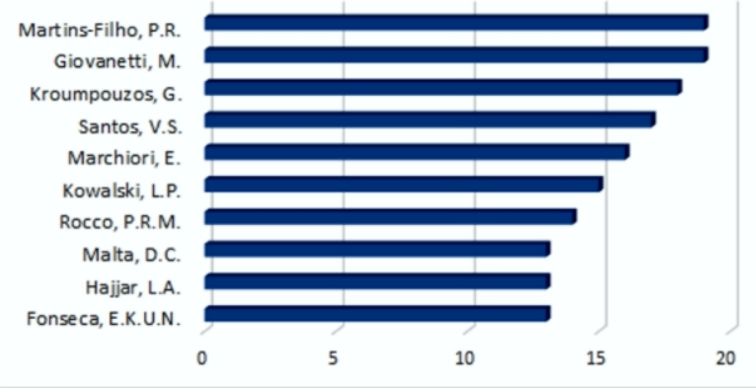

Figura 7: Número de publicações sobre COVID-19 por autor mundo e no Brasil.
Top 10 Instituições Mundo

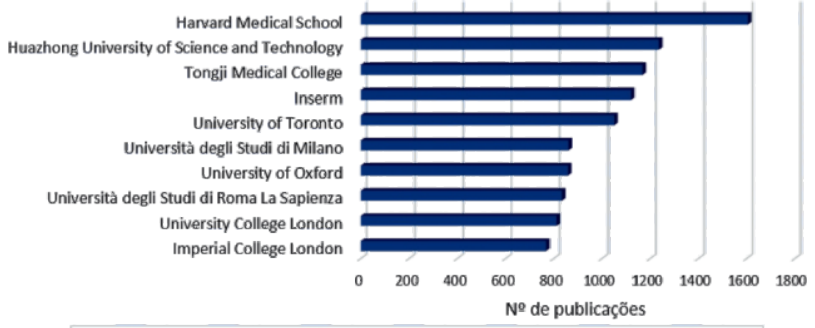

Top 10 Instituições Brasil

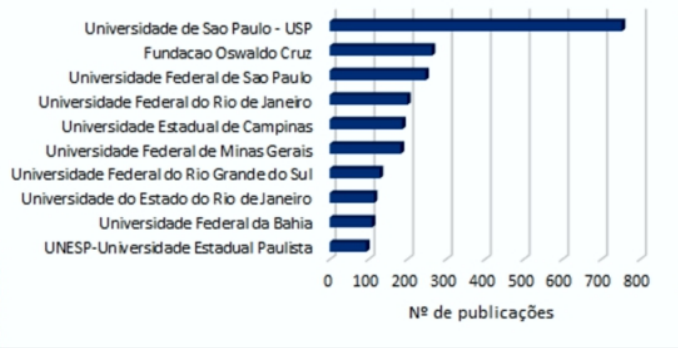

Figura 8: Número de publicações COVID-19 por Instituições no mundo e no Brasil.

Harvard Medical School foi a instituição que mais publicou no mundo, com aproximadamente 1600 publicações. No Brasil, a Universidade de São Paulo obteve mais de 700 publicações sendo, portanto, a que mais publicou.

\section{DISCUSSÃO}

Foi encontrado uma taxa $84 \%$ SF e $90 \%$ SM conforme a FIG 1, para pacientes internados em UTI, os dados corroboram ou não como descrito por ZEZE (2020) onde ela descreve que a taxa de mortalidade foi de $89 \%$. Essas mesmas taxas de óbito quando analisadas frente ao total de prontuários coletados, ou seja, sem considerar o setor do óbito, representam menos de $1 \%$. No início da pandemia, ainda na China, era possível constatar uma taxa de óbito de 45\% (Ruan, et al., 2020).

O tempo médio de internação encontrado foi de dez dias para ambos os sexos, corroborando com os dados descritos por TEICH (2020), no qual descreve que o tempo médio de internação no Brasil é de nove dias. GUAN (2020) descreve que na China o tempo médio de internação foi de doze dias.

A idade média de óbitos foi de 74 anos para o sexo masculino e 68 anos para o sexo feminino, conforme descrito por CAVALCANTE (2020) que descreve que a idade média de óbitos no Rio de Janeiro é de 68 anos. A PREFEITURA DE SÃO PAULO (2020) descreveu que a média de idade de óbitos na 
cidade de São Paulo é de 69 anos.

A taxa de óbito dos pacientes do sexo feminino internados em unidade de terapia intensiva foi de $84 \%$ e do sexo masculino $90 \%$, diferentemente de SAUERESSIG (2020) que descreveu $28,3 \%$ de letalidade em pacientes internalizados.

Os dados analisados mostram uma alta taxa de óbito para os pacientes que evoluíram para internação em UTI, sendo de $90 \%$ para o sexo masculino e $84 \%$ para o feminino, conforme descrito na figura 1 , tais informações se assemelham com o que descreve ZEZE (2020), onde a taxa de mortalidade foi de $89 \%$. Por outro lado, SAUERESSIG (2020) descreveu $28,3 \%$ de letalidade em pacientes internalizados em unidade intensiva, um percentual expressivo a mais do encontrado na pesquisa atual. Porém, ao analisarmos de forma global, ou seja, as mesmas taxas de óbitos, porém, frente ao total de prontuários coletados, sem considerar o setor do óbito, representam menos de $1 \%$. Destaca-se que no início da pandemia, ainda na China, era possível constatar uma taxa de óbito de 45\% (Ruan, et al., 2020). ESCOBAR (2020) descreveu que em Rondônia, até 40 anos os óbitos eram mais prevalentes em mulheres, porém após essa idade foi mais prevalente no sexo masculino.

Já quanto ao tempo médio de internação encontrado, de dez dias, para ambos os sexos, corroborando com os dados descritos por $\mathrm{TEICH}$ (2020), no qual descreve que o tempo médio de internação no Brasil é de nove dias (09). Conforme também descrito por FERGUSON (2020), em que encontrou 10,4 dias a média de hospitalização. GUAN (2020) descreve que na China o tempo médio de internação foi de doze (12) dias.

A idade média de óbitos foi de 74 anos para o sexo masculino e 68 anos para o sexo feminino, conforme descrito por CAVALCANTE (2020) que descreve que a idade média de óbitos no Rio de Janeiro é de 68 anos. A PREFEITURA DE SÃO PAULO (2020) descreveu que a média de idade de óbitos na cidade de São Paulo é de 69 anos. Segundo
BARBOSA (2020) em 2020 as maiores taxas de letalidade acumulada entre os idosos decorrente da COVID-19 foi na Bahia $(56,46 \%)$, Rio de Janeiro (48,10\%) e Pernambuco (40,76\%).

É importante destacar quanto a maior preocupação frente a COVID-19, que é o desfecho morte, o estudo demonstra que há uma pequena taxa de óbito quando visto de forma global, logo, considerando a totalidade da pesquisa, esse dado se torna mais expressivo aos pacientes em regime de tratamento em unidade intensiva, onde o percentual aumenta consideravelmente.

\section{CONCLUSÃO}

A taxa do município de Campos dos Goytacazes foi menor que a taxa do Estado do Rio de Janeiro e inferior também a taxa nacional.

Pode-se perceber que o tempo de internação é semelhante entre homens e mulheres em UTI.

A taxa de óbitos é maior em idosos, e no sexo masculino é ainda maior.

A grande maioria dos óbitos ocorrem em UTIs.

O Brasil tem forte participação nas publicações mundiais sobre COVID-19 via Scopus.

Mais de $99 \%$ das publicações mundiais sobre COVID-19 ocorreram em 2020.

Os resultados encontrados evidenciam que os pacientes, na sua maioria, receberam tratamento domiciliar.

A taxa de óbitos é maior em idosos, uma vez que a imunossenescência aumenta a susceptibilidade a doenças infectocontagiosas, sendo importante destacar que nessa faixa etária é mais prevalente comorbidades, estes apresentam um desfecho mais desfavorável.

Mais de $99 \%$ das publicações mundiais sobre COVID-19 ocorreram em 2020, devido ao grande aumento do número de casos e impacto mundial da pandemia, com destaque para o Brasil que, segundo a base Scopus, teve grande participação nas publicações mundiais sobre o tema.

\section{REFERÊNCIAS}

1. Wang, G., Wu, C., Zhang, Q., Yu, B., Lü, J., Zhang, S. e altri. Clinical characteristics and the risk factors for severe events of elderly Coronavirus disease 2019 patients. Journal of Central South University (Medical Sciences). 2020 mag 1;45(5). https://doi.org/10.11817/j.issn.1672-7347.2020.200292

2. Wang, R., Pan, M., Zhang, X., et al. Epidemiological and clinical features of 125 Hospitalized Patients with COVID-19 in Fuyang, Anhui, China. Int J Infect Dis. 2020;95:421-428. doi:10.1016/j.ijid.2020.03.070 
3. Tian, S., Chang, Z., Wang, Y., et al. Clinical Characteristics and Reasons for Differences in Duration From Symptom Onset to Release From Quarantine Among Patients With COVID-19 in Liaocheng, China. Front Med (Lausanne). 2020;7:210. Published 2020 May 12. doi:10.3389/fmed.2020.00210

4. Guan, WJ., Ni, ZY., Hu, Y., et al. Clinical Characteristics of Coronavirus Disease 2019 in China. N Engl J Med. 2020;382(18):1708-1720. doi:10.1056/NEJMoa2002032

5. Joseli Maria da Rocha Nogueira, Líllian Oliveira Pereira da Silva. The laboratory diagnosis of COVID-19 in Brazil. Brazilian Journal of Clinical Analyses. DOI: 10.21877/2448-3877.20200007. Disponível em http://www.rbac.org.br/artigos/diagnostico-laboratorial-da-covid-19-no-brasil/

6. TEICH, Vanessa Damazio et al . Características epidemiológicas e clínicas dos pacientes com COVID-19 no Brasil. Einstein (São Paulo), São Paulo, v. 18, eAO6022, 2020. Available from <http://www.scielo.br/scielo.php?script=sci_arttext\&pid=S1679-45082020000100260\&lng=en\&nrm=iso>. access on 22 Feb. 2021. Epub Aug 14, 2020. https://doi.org/10.31744/einstein_journal/2020ao6022. 7. Principais artigos científicos sobre a COVID-19 publicados em fevereiro. Sociedade Brasileira de Pneumologia e Tisiologia (SBPT), 2021. Disponível em: https://sbpt.org.br/portal/resumo-cientifico-covid-1/

8. CAVALCANTE, João Roberto; ABREU, Ariane de Jesus Lopes de. COVID-19 no município do Rio de Janeiro: análise espacial da ocorrência dos primeiros casos e óbitos confirmados. Epidemiol. Serv. Saúde, Brasília, v. 29, n. 3, e2020204, 2020. Available from <http://www.scielo.br/scielo.php?script=sci_arttext\&pid=S223796222020000300302\&Ing=en\&nrm=iso>. access on 26 Feb. 2021. Epub June 03, 2020. https://doi.org/10.5123/s1679-49742020000300007.

9. https://www.saopaulo.sp.gov.br/noticias-coronavirus/sp-media-movel-semanal-de-mortes-por-covid-19chega-a-84-obitos-neste-sabado/

10. Mauricio Guidi Saueressig, Cristiano Lima Hackmann, Carlos Eduardo Schonerwald da Silva, Jair Ferreira. Estimativa de pacientes hospitalizados por COVID-19 em unidade de terapia intensiva no pico da pandemia em Porto Alegre: Estudo com modelo epidemiológico SEIHDR DOI: 10.1590/SciELOPreprints.1080.

11. Gutiérrez Suárez Jennifer Carolina, Almonacid Urrego Carmen Cecilia, Hernández Rojas Edith del Carmen, Mendieta Zerón Hugo. Valor pronóstico de los marcadores bioquímicos en pacientes con COVID-19. Nova [Internet]. 2020 Dec [cited 2021 Feb 06] ; 18( spe35 ): 53-60. Available from: http://www.scielo.org.co/scielo.php?script=sci_arttext\&pid=S1794-24702020000300053\&lng=en. Epub Jan 15, 2021. http://dx.doi.org/10.22490/24629448.4186.

12. Brandão Simone Cristina Soares, Godoi Emmanuelle Tenório Albuquerque Madruga, Ramos Júlia de Oliveira Xavier, Melo Leila Maria Magalhães Pessoa de Dompieri Luca Terracini, Brindeiro Filho Djair Falcão et al. Papel do Endotélio na COVID-19 Grave. Arq. Bras. Cardiol. [Internet]. 2020 Dec [cited 2021 Feb 06]; 115 (6): 11841189. Available from: http://www.scielo.br/scielo.php?script=sci_arttext\&pid=S0066-

782X2020001401184\&Ing=en. Epub Jan 18, 2021. https://doi.org/10.36660/abc.20200643.

13. Alves Cunha Ana Luisa, Quispe Cornejo Armin A. Ávila Hilari Adrián, Valdivia Cayoja Adolfo, Chino Mendoza Juan Manuel, Vera Carrasco Oscar. Breve história e fisiopatologia de covid-19. Quad. - Hosp. Clin. [Internet]. 2020 julho [citado 2021 fevereiro 06]; 61 (1): 130-143. Disponível em: http://www.scielo.org.bo/scielo.php?script=sci_arttext\&pid=S1652-67762020000100011\&lng=es. 14. Floriani Isabela Dombeck, Borgmann Ariela Victoria, Barreto Marina Rachid, Ribeiro Elaine Rossi. EXPOSURE OF PEDIATRIC EMERGENCY PATIENTS TO IMAGING EXAMS, NOWADAYS AND IN TIMES OF COVID-19: AN INTEGRATIVE REVIEW. Rev. paul. pediatr. [Internet]. 2022 [cited 2021 Feb 06]; 40: e2020302. Available from: http://www.scielo.br/scielo.php?script=sci_arttext\&pid=S0103-05822022000100501\&lng=en. Epub Dec 18, 2020. https://doi.org/10.1590/1984-0462/2022/40/2020302.

15. FALAVIGNA, Maicon. Diretrizes para o tratamento farmacológico da COVID-19. Consenso da Associação de Medicina Intensiva Brasileira, da Sociedade Brasileira de Infectologia e da Sociedade Brasileira de Pneumologia e Tisiologia. Rev. bras. ter. intensiva, São Paulo, ano 2020, v. 32, n. 2, p. 4335, 13 jul. 2020.

16. Asselah T, Durantel D, Pasmant E, Lau G, Schinazi RF. COVID-19: Discovery, diagnostics and drug development. J Hepatol. 2021 Jan;74(1):168-184. doi: 10.1016/j.jhep.2020.09.031. Epub 2020 Oct 8. PMID: 33038433; PMCID: PMC7543767.

17. Brüssow H. Immunology of COVID-19. Environ Microbiol. 2020 Dec;22(12):4895-4908. doi: 10.1111/1462- 
2920.15302. Epub 2020 Nov 25. PMID: 33145867.

18. ELSEVIER 2018, Scopus. Amsterdam: Elsevier.

19. Mesquita R, Brambilla S, Laipelt RCF, Maia F, Vanz S, Caregnato S. Elaboração e aplicação de instrumentos para avaliação da base de dados Scopus. Perspectivas em Ciência da Informação. 2006; 11: 187-205.

20. ARAÚJO, Carlos Alberto. Bibliometria: evolução histórica e questões atuais. Em Questão, Porto Alegre, v. 12, n. 1, p. 11-32, jan./jun. 2006.

21. MARTINS, Maria de Fátima Moreira. Análise bibliométrica de artigos científicos sobre o vírus Zika. Revista Eletrônica de Comunicação, Informação e Inovação em Saúde, Rio de Janeiro, v.1, n.10, p.1 - 9, jan.- mar. 2016. 22. Ruan Q, Yang K, Wang W, Jiang L, Song J. Clinical predictors of mortality due to COVID-19 based on an analysis of data of 150 patients from Wuhan, China. Intensive Care Med. 2020 May;46(5):846-8.

23. Boletim Coronavírus - 10/12/2020. campos.rj.gov.br/, 2020. Disponível em:

https://www.campos.rj.gov.br/exibirNoticia.php?id_noticia=59267

24. Boletim Coronavírus - 19/12/2020. saude.rj.gov.br, 2020. Disponível em:

https://www.saude.rj.gov.br/noticias/2020/12/boletim-coronavirus-0112

25. Brasil registra 52 mil casos de Covid em 24 horas. G1, 2020. Disponível em:

https://g1.globo.com/bemestar/coronavirus/noticia/2020/12/01/casos-e-mortes-por-coronavirus-nobrasil-em-1-de-dezembro-segundo-consorcio-de-veiculos-de-imprensa.ghtml

26. Canabarro A, Tenório E, Martins R, Martins L, Brito S, Chaves R (2020) Estudo orientado por dados da pandemia de COVID-19 por meio de modelagem estruturada por idade e previsão do fracasso do sistema de saúde no Brasil em meio a diversas estratégias de intervenção. PLoS ONE 15(7): e0236310.

https://doi.org/10.1371/journal.pone.0236310

27. Ferguson NM, Laydon D, Nedjati-Gilani G, Imai N, Ainslie K, Baguelin M, et al. Impact of non-pharmaceutical interventions (NPIs) to reduce COVID-19 mortality and healthcare demand. London: Imperial College COVID-19 Response Team; 2020.

28. Escobar, Ana Lúcia, Rodriguez, Tomás Daniel Menéndez e Monteiro, Janne CavalcanteLetalidade e características dos óbitos por COVID-19 em Rondônia: estudo observacional. Epidemiologia e Serviços de Saúde [online]. 2021, v. 30, n. 1 [Acessado 21 Julho 2021] , e2020763. Disponível em:

<https://doi.org/10.1590/S1679-49742021000100019>. Epub 18 Dez 2020. ISSN 2237-9622. https://doi.org/10.1590/S1679-49742021000100019.

29. Salvati, L., Biagioni, B., Vivarelli, E. et al. Uma lupa com gênero no COVID-19. Clin Mol Allergy 18, 14 (2020). https://doi.org/10.1186/s12948-020-00129-2

30. Barbosa, Isabelle Ribeiro et al. Incidence of and mortality from COVID-19 in the older Brazilian population and its relationship with contextual indicators: an ecological study. Revista Brasileira de Geriatria e Gerontologia [online]. 2020, v. 23, n. 01 [Acessado 21 Julho 2021] , e200171. Disponível em: <https://doi.org/10.1590/198122562020023.200171>. Epub 07 Out 2020. ISSN 1981-2256. https://doi.org/10.1590/1981-

22562020023.200171. 